\title{
OS CONCURSOS PARA O CARGO DE SECRETÁRIO EXECUTIVO NAS INSTITUIÇÕES FEDERAIS DE ENSINO SUPERIOR
}

\author{
PUBLIC SERVICE ENTRANCE EXAMINATIONS FOR EXECUTIVE \\ SECRETARY POSITION IN FEDERAL INSTITUTIONS OF HIGHER \\ EDUCATION
}

\section{Luciana Nunes de Oliveira}

Mestre em Administração pela Universidade Federal do Rio Grande do Sul - UFRGS, Rio Grande do Sul (Brasil). Secretária Executiva pela Universidade Federal de Santa Maria UFSM, Rio Grande do Sul (Brasil).E-mail: nunesoliveira.luciana@hotmail.com

\section{Marina Lopes Soares}

Pós-graduada em Gestão Estratégica da Comunicação Organizacional pelo Centro Universitário UMA, Minas Gerais (Brasil). Analista de Carga Internacional na Internacional Comissária de Despachos Aduaneiros Ltda, Minas Gerais (Brasil). E-mail: marina lopesec@yahoo.com.br

\section{Ludmila Maria Martins de Oliveira}

Bacharel em Secretariado Executivo Trilíngue pela Universidade Federal de Viçosa - UFV, Minas Gerais (Brasil). Assistente em Administração pela Universidade Federal de Viçosa UFV, Minas Gerais (Brasil). E-mail: martinsoliveira.lud@gmail.com

\section{Nanci Fernandes de Paula}

Bacharel em Secretariado Executivo Trilíngue pela Universidade Federal de Viçosa - UFV, Minas Gerais (Brasil). Secretária Executiva pela Fundação Arthur Bernardes - FUNARBE, Minas Gerais (Brasil). E-mail: nancipaula@gmail.com 


\title{
OS CONCURSOS PARA O CARGO DE SECRETÁRIO EXECUTIVO NAS INSTITUIÇÕES FEDERAIS DE ENSINO SUPERIOR
}

\begin{abstract}
RESUMO
O profissional com formação acadêmica em Secretariado Executivo está a cada dia mais inserido no mercado de trabalho, tanto no setor privado como no público. Porém, os certames públicos lançados atualmente, por diversas vezes apontam vagas para o cargo de secretário executivo, no qual para a investidura nesse cargo não necessariamente é obrigatório o curso superior de Secretariado Executivo, tampouco habilitação profissional, possibilitando que graduados em diversas áreas do conhecimento ingressem no setor público como "secretários executivos". Diante do exposto, o presente artigo teve como objetivo identificar e apresentar, no âmbito do setor público, especificamente nas Instituições Federais de Ensino Superior (IFES), no período compreendido entre 2009 a 2015, as exigências e critérios estabelecidos para os concursos públicos destinados a secretários executivos. Foram identificados 110 editais que disponibilizaram 531 vagas, sendo que somente 308 vagas (de 57 editais) foram exclusivamente destinadas aos candidatos habilitados profissionalmente, de acordo com a Lei $n^{\circ} 7.377$ de 30 de setembro de 1985. Foi possível perceber que algumas IFES não exigiram em seus editais a habilitação profissional conforme Ofício Circular $\mathrm{n}^{\circ}$ 015/2005 do MEC (Ministério da Educação), ocasionando um prejuízo ao profissional que possui a habilitação profissional.
\end{abstract}

Palavras chave: Secretário executivo. Concurso público. Instituições Federais de Ensino Superior. 


\title{
PUBLIC SERVICE ENTRANCE EXAMINATIONS FOR EXECUTIVE SECRETARY POSITION IN FEDERAL INSTITUTIONS OF HIGHER EDUCATION
}

\begin{abstract}
The professional with a bachelor in Secretarial Science is increasingly placed on the labor market, both in the private and the public sector. However, recent public service entrance examination, on several occasions, offer positions for executive secretary - in which, neither the undergraduate degree in Secretarial Science nor the professional registry is mandatory, allowing undergraduates in different areas enter the public sector as executive secretaries. On the above, this article aims at identifying and introduce the public service entrance examinations for executive secretary, specifically in the Federal Institutions of Higher Education (IFES), from 2009 to 2015. It was identified 110 public service entrance examination rules which provided 531 positions. Of these, only 308 positions (from 57 public service entrance examination rules) were exclusively intended for applicants professionally qualified according to the Law No 7.377 of September 30th, 1985. It was noted that some IFES did not demand, in their public service entrance examination rules, the professional qualification required by the Circular Letter No 015/2005 from MEC, causing a loss to the professionals with the professional qualification.
\end{abstract}

Keywords: Executive secretary. Public service entrance examination. Federal Institutions of Higher Education. 


\section{INTRODUÇÃO}

O profissional com formação acadêmica em Secretariado Executivo, diante do aumento do número de graduados na área e do reconhecimento da profissão, está a cada dia mais inserido no mercado de trabalho, tanto no setor privado como no público. Estudos de Cardoso Júnior e Nogueira (2011) e Moraes (2014) apontam que o governo iniciado em 2003 até os dias atuais retomou os concursos públicos no país, até então estagnados nos governos anteriores. Tais estudos mostraram que 155 mil novos servidores foram admitidos entre 2003 e 2010.

Contudo, apesar de o secretariado ser uma profissão reconhecida por lei, os profissionais da área ainda concorrem em concursos públicos com profissionais diversos, sem formação acadêmica na área, dificultando ou impossibilitando a inserção de bacharéis, técnicos e tecnólogos em Secretariado, tendo em vista que, com base nos dados verificados no desenvolvimento deste trabalho, os conhecimentos específicos na área são pouco valorizados nas provas.

Essa dificuldade é perceptível nos certames públicos lançados atualmente, que por diversas vezes apontam vagas para o cargo de secretário executivo, não sendo necessariamente o requisito para investidura o curso superior de Secretariado Executivo ou o curso superior em Tecnologia em Secretariado, possibilitando que graduados em diversas áreas do conhecimento ingressem no setor público como "secretários executivos". Tal conjuntura, por sua vez, diverge do estabelecido pela lei que regulamenta a profissão, a qual estabelece que secretário executivo é "o profissional diplomado no Brasil por Curso Superior de Secretariado, legalmente reconhecido, ou diplomado no exterior por Curso Superior de Secretariado, cujo diploma seja revalidado na forma da lei” (Lei 9.261, 1996).

Diante do exposto, o presente artigo tem como objetivo identificar e apresentar, no âmbito do setor público, especificamente nas IFES, no período compreendido entre 2009 a 2015, os concursos destinados a secretários executivos e a exigibilidade de habilitação profissional, garantindo, dessa forma, o ingresso de profissionais com formação na área. Esse período foi adotado por retratar os últimos cinco anos.

Além disso, será apresentado um panorama da oferta de vagas para o cargo de secretário executivo nas IFES no período de 2009 a 2015, com o objetivo de saber quais 
as instituições que ofertaram o concurso público para Secretário Executivo e consequentemente em quais regiões/estados estão ofertando a maior quantidade de vagas para este cargo.

O motivo pela escolha das IFES deve-se ao Plano de Carreira dos Cargos de Técnico-administrativos em Educação (PCCTAE), que é regido pela Lei ${ }^{0} 11.091$, de 12 de janeiro de 2005, que aponta como requisito para o cargo de secretário executivo "Curso Superior em Letras ou Secretário Executivo Bilíngue (sic)” (Lei 11.091, 2005).

Este artigo divide-se em três sessões, além das considerações finais. Na primeira sessão é realizada uma breve revisão de literatura que traz um histórico sobre concursos públicos, PCCTAE e a formação e atuação do profissional de Secretariado Executivo. A segunda sessão aborda o método utilizado para a consecução dos objetivos do presente estudo. A terceira sessão traz a análise e a discussão dos dados.

\section{REVISÃO DE LITERATURA}

Nesta seção é apresentada uma revisão de literatura acerca dos seguintes temas: Concursos públicos, Plano de Carreira dos Cargos de Técnico-administrativos em Educação e a formação e atuação do profissional de Secretariado Executivo.

\section{Concursos públicos}

O Estado, de acordo com o exposto por Carvalho (2009), quando exerce as competências que lhe conferem, necessita compor uma equipe capaz de satisfazer as necessidades da coletividade. São necessários profissionais que façam parte de uma estrutura voltada ao desempenho do interesse público primário, aliada à realização pessoal.

Carvalho (2009) nos mostra ainda que em uma visão histórica, observa-se que as formas utilizadas pelo Estado para a seleção dos seus agentes variavam desde o sorteio, passando pela sucessão hereditária, o arrendamento, a compra e venda e a nomeação absoluta, chegando enfim ao concurso, já no século XXI, como forma de avaliação para 
a escolha dos melhores candidatos disponíveis para integrar o corpo administrativo do Estado.

Dessa forma, "o concurso admite a inserção de novos atores sociais que podem ser provenientes da classe média ou das camadas mais pobres da população, o que resultará em mobilidade social pelo critério merecimento" (Carvalho, 2009), permitindo, pois, que qualquer cidadão possa ter uma participação efetiva na administração pública, além de eliminar pessoas despreparadas e optar por aqueles que tendem a ter um melhor desempenho e seja mais qualificado para desenvolver as competências do serviço público.

Para Fontainha, Geraldo, Veronese, Alves, Figueiredo e Waldburguer (2014, p. 12) como corda estendida entre o mundo escolar e o profissional, os concursos chegam à contemporaneidade com duas ideologias tributárias da sua história: a ideologia acadêmica e a ideologia profissional. A ideologia acadêmica recruta os melhores egressos do sistema de ensino. Ela primará por formas de avaliação similares às da escola ou da universidade por docentes dessas instituições nas bancas e por uma formação profissional posterior ao certame. Este é o primado da meritocracia escolar. A ideologia profissional vai recrutar os jovens profissionais mais competentes, que já apresentam as habilidades necessárias ao exercício do futuro cargo. Ela primará por formas de avaliação similares às rotinas de trabalho da futura atividade (provas práticas) por profissionais ou mesmo membros já recrutados da carreira na banca e por um aprimoramento continuado posterior ao certame.

No Brasil, a Constituição de 1988 fez do concurso público a única via de ingresso em cargo ou emprego público, fazendo com que o Supremo Tribunal Federal decidisse que a maioria dos modos derivados de investidura (mudança de cargo mediante procedimentos internos, tais como o acesso, transposição, progressão) não fosse recepcionada pelo novo regime, estando proibida (Pereira, 2009).

Fontainha et al. (2014, p. 18) formularam um quadro das normas jurídicas referentes aos concursos públicos, sejam elas legais ou regulamentares. Elas estão submetidas a alguns incisos do artigo 37 da Constituição Federal de 1988, como indicado no Quadro 1 a seguir: 
Quadro 1. Constituição Federal (dispositivos centrais - gerais).

\begin{tabular}{|l|}
\hline \multicolumn{1}{|c|}{ Constituiçăo Federal (dispositivos centrais - gerais) } \\
\hline Art. 37, I (amplo acesso aos cargos, empregos e funçōes públicas). \\
\hline Art. 37, II (universalidade do concurso público prévio para admissão). \\
\hline Art. 37, III (validade dos concursos e possibilidade de sua prorrogação). \\
\hline Art. 37, IV (observância da lista sequencial de aprovados para nomeação). \\
\hline $\begin{array}{l}\text { Art. 37, VIII - a lei reservará percentual dos cargos e empregos públicos para as } \\
\text { pessoas portadoras de deficiência e definirá os critérios de sua admissão. }\end{array}$ \\
\hline Art. 37, IX (exceção para contrataçāo de servidores temporários). \\
\hline
\end{tabular}

Fonte: Fontainha et al. (2014, p. 18)

Atualmente, para Moraes (2014), o governo em vigência no período de realização da pesquisa aumentou consideravelmente o emprego público, retomando os concursos públicos em diversas áreas. De acordo com Cardoso Júnior e Nogueira (2011), o movimento de recomposição de pessoal no setor público brasileiro, observado durante toda a primeira década de 2000 foi suficiente para repor praticamente o mesmo estoque e percentual de servidores ativos existentes em meados da década de 1990.

Ainda conforme Cardoso Júnior e Nogueira (2011, p. 239)

o significado da retomada do concurso público para crescimento e fortalecimento da capacidade de Estado fica bem evidenciado na Figura 1, que consolida a série de admitidos anualmente a partir dos governos Collor e Itamar, durante os quais não houve admissão de servidores por essa via. Nada menos que 155 mil novos servidores foram admitidos entre 2003 e 2010.

Figura 1. Servidores Civis Federais: aposentados e admitidos por concurso.

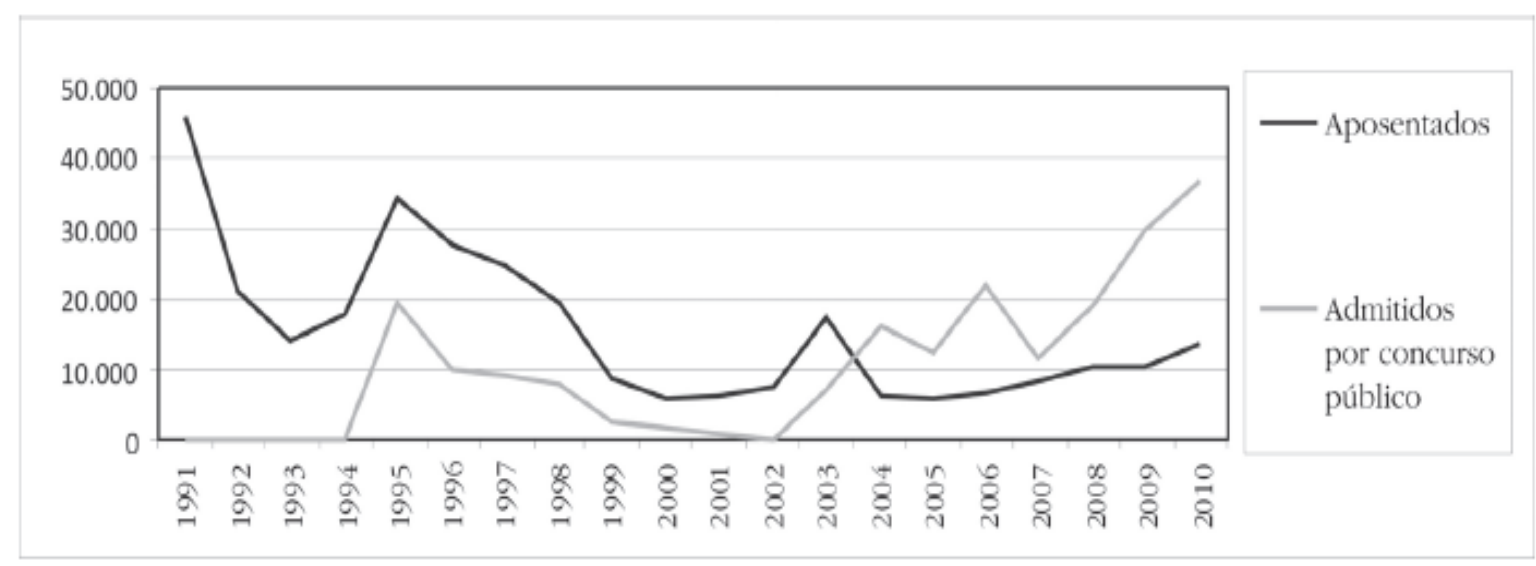

Fonte: Júnior e Nogueira (2011, p. 239)

Revista de Gestão e Secretariado-GeSec, São Paulo, v. 7, n. 3, p 202-225, set./dez. 2016. 
Do ponto de vista qualitativo, evidências do estudo de Cardoso Júnior e Nogueira (2011) indicam que o movimento atual de recomposição de pessoal no setor público deve trazer melhorias gradativas ao desempenho institucional, talvez ainda pouco perceptíveis devido ao insuficiente tempo de maturação do novo contingente de força de trabalho a serviço do Estado.

Para Melo (2008), a universidade precisa criar mecanismos de capacitação de dirigentes que tenham formação específica na área de gestão universitária, e que sejam preparados para gerenciar um sistema moderno de interação com a sociedade e seus diversos setores, entre eles o empresarial. Dirigentes que saibam administrar e conviver com os entraves burocráticos próprios da administração pública, mas que sejam capazes de ser e fazer pensar, criativo a equipe.

Além disso, tais dirigentes precisam ter uma visão ampla das novas competências requeridas pela sociedade e pela universidade, ou seja, que consigam rapidamente por meio de uma demanda constituída, identificar os grupos, laboratórios e indivíduos capazes de responder e atender as necessidades sociais requeridas (Melo, 2008).

Para Oliveira e Silva (2011), a gestão contemporânea de pessoas no contexto das IFES foi efetivada por meio do PCCTAE, instituído pela Lei $\mathrm{n}^{\circ}$ 11.091, de 12 de janeiro de 2005, assunto que será discutido na próxima subseção.

\section{Plano de carreira dos técnico-administrativos em educação}

A reestruturação da carreira dos técnico-administrativos em educação está disposta na Lei 11.091 de 12 de janeiro de 2005. O plano de carreira está estruturado em cinco níveis de classificação: A (alfabetizado/ nível fundamental incompleto), B (nível fundamental incompleto), C (ensino fundamental), D (ensino médio) e E (ensino superior); e com quatro níveis de capacitação (Brasil, 2005). O ingresso na carreira se dá por meio de concurso público, sendo que o exercício é iniciado no padrão do primeiro nível de capacitação segundo a classificação do cargo, considerando as especificidades de cada carreira.

De acordo com o parágrafo $2^{\circ}$ da referida Lei

o edital definirá as características de cada fase do concurso público, os requisitos de escolaridade, a formação especializada e a experiência profissional, os critérios 
eliminatórios e classificatórios, bem como eventuais restrições e condicionantes decorrentes do ambiente organizacional ao qual serão destinadas as vagas (Lei 11.091, 2005).

Para Oliveira e Silva (2011), o PCCTAE estabeleceu novos paradigmas para a estruturação dos cargos dentro das IFES. A hierarquia dos cargos foi organizada por critérios que contemplam além das exigências de escolaridade para o exercício das atividades, outros requisitos e habilidades necessárias, tais como responsabilidade, conhecimentos, habilidades específicas, formação especializada, experiência, risco e esforço físico, resultando em uma configuração mais definida das necessidades institucionais.

Anterior ao PCCTAE, os técnico-administrativos das IFES eram regidos pelo Plano Único de Classificação e Retribuição de Cargos e Empregos (PUCRCE), instituído pela Lei $\mathrm{n}^{\circ}$ 7.596, de 10 de abril de 1987. De acordo com Oliveira e Silva (2011), O PCCTAE é considerado, para todos os efeitos, um avanço quando comparado ao PUCRCE, pois simplificou os trâmites burocráticos legais.

\section{Formação e atuação do profissional de Secretariado Executivo}

De acordo com Schumacher, Portela e Borth (2013), a origem do secretário executivo remonta às civilizações antigas por meio das atividades dos escribas: homens que tinham o domínio da escrita, faziam as contas, arquivavam, redigiam as ordens, eram capazes de recebê-las por escrito, e, por conseguinte, encarregados de sua execução.

Segundo Mazulo e Liendo (2010), no Brasil, com a chegada da indústria automobilística na década de 1950, observou-se a valorização da força de trabalho da mulher na função de secretária. Também nessa década, iniciou-se o processo de engrandecimento da profissão, pois o mercado começou a requerer desse profissional uma melhor qualificação e um perfil específico e diferenciado.

$\mathrm{Na}$ "era da globalização", o secretário passa a ter várias atribuições no cenário competitivo das organizações. No passado, suas funções estavam restritas às tarefas de datilografar cartas, servir café, organizar agendas e atender somente a um chefe. Com o decorrer do tempo, as modificações administrativas oriundas da globalização fizeram com que a função do secretário fosse repensada (Santos \& Caimi, 2009). 
A sociedade empresarial não se satisfaz com profissionais de secretariado que apenas tenham como diferencial alto desempenho em tarefas rotineiras e técnicas. Exige-se que estes profissionais participem de reuniões com poder de articulação, possuam pleno conhecimento do negócio da instituição onde atuam, tenham conhecimento dos potenciais concorrentes, assim como dos objetivos organizacionais e em muitos momentos são convidados a participar da elaboração estratégica destes frente à dinâmica organizacional (Schumacher et al., 2013).

Para Mazulo e Liendo (2010), o profissional de Secretariado é um assessor, um profissional do qual se esperam resultados obtidos por meio de seu sólido conhecimento técnico, pelo domínio operacional de equipamentos, por sua habilidade pessoal e também pela coordenação de alguns serviços e pessoas.

O profissional de Secretariado Executivo gerencia sua rotina e tem poder de decisão em algum momento do seu dia e ignora a expressão "braço direito do chefe" para assumir a postura de facilitador do dia a dia do executivo com o qual trabalha (Mazulo \& Liendo, 2010).

Ao atuar como agente facilitador, o profissional de Secretariado Executivo revela seu desempenho na rede de relações interpessoais que administra, sendo nesta rede que imprimirá sua marca. Sua percepção do ambiente, das pessoas, dos códigos ditos e daqueles implícitos na linguagem não verbal, o equilíbrio emocional, a visão da empresa como um todo, a criatividade na relação personalizada com o cliente, tudo isso facilitará o dia a dia com o executivo, colegas, clientes e fornecedores (Neiva \& D’Elia, 2009).

O Quadro 2 traz um resumo da evolução da profissão de Secretariado Executivo apresentado por Neiva e D’Elia (2009). 
Luciana Nunes de Oliveira, Marina Lopes Soares, Ludmila Maria Martins de Oliveira e Nanci Fernandes de Paula

Quadro 2. Perfil do profissional secretário

\begin{tabular}{|c|c|c|}
\hline Ontem & Década de 90 & Séc. XXI \\
\hline $\begin{array}{l}\text { Formação dispersiva, } \\
\text { autodidatismo. }\end{array}$ & $\begin{array}{c}\text { Existência de cursos específicos para } \\
\text { formação. }\end{array}$ & $\begin{array}{l}\text { Amadurecimento profissional - } \\
\text { código de ética. }\end{array}$ \\
\hline $\begin{array}{c}\text { Falta de qualquer requisito para o } \\
\text { aprimoramento. }\end{array}$ & $\begin{array}{l}\text { Cursos de reciclagem e de } \\
\text { conhecimentos peculiares. }\end{array}$ & $\begin{array}{l}\text { Constante aprimoramento e } \\
\text { desenvolvimento contínuo. }\end{array}$ \\
\hline $\begin{array}{l}\text { Ausência de política para } \\
\text { recrutamento e seleção. }\end{array}$ & $\begin{array}{l}\text { Exigência de qualificação e definição } \\
\text { de atribuições e plano de carreira. }\end{array}$ & $\begin{array}{c}\text { Visão holística e trabalho em equipe, } \\
\text { consciência profissional. }\end{array}$ \\
\hline $\begin{array}{c}\text { Organizações burocráticas com } \\
\text { tarefas isoladas. }\end{array}$ & $\begin{array}{l}\text { Organizações participativas, tarefas } \\
\text { definidas, trabalho com qualidade, } \\
\text { criatividade e participação. }\end{array}$ & $\begin{array}{l}\text { Organizações empreendedoras, } \\
\text { trabalho em equipe, visão global, } \\
\text { metodologia flexível, divisão de } \\
\text { responsabilidade. }\end{array}$ \\
\hline Tarefas traçadas pela chefia. & $\begin{array}{l}\text { Tarefas definidas pelo novo estilo } \\
\text { gerencial. }\end{array}$ & $\begin{array}{c}\text { Tarefas globais com autonomia para } \\
\text { execução. }\end{array}$ \\
\hline Secretário como função. & Secretário como profissão. & $\begin{array}{l}\text { Secretário com reconhecimento } \\
\text { profissional e comprometido com } \\
\text { resultados. }\end{array}$ \\
\hline $\begin{array}{c}\text { Objetivo de trabalho determinado } \\
\text { pelo poder da chefia. }\end{array}$ & $\begin{array}{l}\text { Objetivo de trabalho definido pela } \\
\text { necessidade do mercado. }\end{array}$ & $\begin{array}{l}\text { Objetivo do trabalho definido pela } \\
\text { equipe empreendedora. }\end{array}$ \\
\hline Falta de recursos. & $\begin{array}{l}\text { Domínio em informática e outros } \\
\text { conhecimentos. }\end{array}$ & $\begin{array}{c}\text { Necessidade constante de } \\
\text { aprimoramento e de novos } \\
\text { conhecimentos e de visão do negócio. }\end{array}$ \\
\hline Chefia. & Executivo. & Parceria. \\
\hline
\end{tabular}

Fonte: Neiva e D'Elia (2009)

Para Santos e Caimi (2009), em um cenário de acentuado desenvolvimento científico e de profundas inovações nas tecnologias de produção, os profissionais de Secretariado Executivo são desafiados a desempenhar com maior nível de competência as tarefas relacionadas à profissão, com o objetivo de contribuir para a melhoria da qualidade e a ampliação da produtividade nas organizações.

Atualmente, o profissional de Secretariado é o maior apoio para o gestor em todos os níveis gerenciais, considerado o profissional com o maior nível de competências organizacionais, capaz de assumir responsabilidades sem ter a necessidade de ser comandado diretamente, ou seja, é qualificado para implementar as decisões e 
responsabilidades assumidas, além de tomar decisões dentro dos limites de sua autoridade (Halici; Yilmaz \& Kasimoglu, 2011).

\section{MÉTODO}

De acordo com os objetivos propostos, trata-se de uma pesquisa descritiva, que de acordo com Gil (2002), busca descrever as características de determinada população ou fenômeno e, também, demonstrar o estabelecimento de relações entre variáveis, além de se preocupar em identificar quais os fenômenos que são gerados pelos fatores determinados por esta relação. Este trabalho possui um desenho transversal, pois a coleta de dados foi "realizada de forma episódica uma vez, em tempo de conveniência" (Gonçalves \& Meirelles, 2004, p. 38).

Com relação ao meio de coleta de dados, de acordo com Laville e Dionne (1999) tratou-se de uma pesquisa com dados existentes do tipo documental, pois a fonte de coleta restringiu-se a documentos escritos em formato eletrônico digital. As informações obtidas foram de fontes primárias, no caso, os editais das IFES para provimento de cargos técnico-administrativos, disponíveis nos sites das Instituições.

A população do estudo foram instituições de ensino superior categorizadas como públicas federais (categoria administrativa) e ativas no site E-mec até 31/12/2015. A população contou com 107 IFES. A amostra estudada foram as IFES que abriram editais para concursos para provimento de vagas ao cargo de Secretário Executivo nos anos de 2009 a 2015. É importante ressaltar que foram consideradas as IFES que lançaram o edital de abertura de concurso em 2008, entretanto, as provas ocorreram no ano de 2009. Foram identificados 110 editais para concursos públicos nas IFES da amostra do estudo.

A análise dos dados foi feita por meio de análise descritiva simples. 


\section{ANÁLISE E DISCUSSÃO DOS DADOS}

\section{O caso}

De acordo com anexo II da Lei 11.091, para ingresso no cargo de Secretário Executivo na carreira de Técnico-administrativo em Educação o requisito é curso superior em Letras ou Secretário (sic) Executivo Bilíngue (Lei 11.091, 2005). Esse cargo, por exigir formação de nível superior, é considerado dentro da escala de classificação, como sendo de nível E.

No entanto, para a investidura no cargo de Secretário Executivo, o Ofício Circular no 015/2005/CGGP/SAA/SE/MEC, de 28 de novembro de 2005, diz que além do curso superior em Letras e Secretário (sic) Executivo Bilíngue, é necessário estar habilitado profissionalmente de acordo com a Lei $\mathrm{n}^{\circ} 7.377$ de 30 de setembro de 1985, que dispõe sobre a profissão de Secretário (Ministério da Educação e Cultura [MEC], 2005).

A lei que dispõe sobre o exercício da profissão de Secretário estabelece que é considerado secretário executivo, de acordo com os itens a e b do inciso I

o profissional diplomado no Brasil por Curso Superior de Secretariado, legalmente reconhecido, ou diplomado no exterior por Curso Superior de Secretariado, cujo diploma seja revalidado na forma da lei; e o portador de qualquer diploma de nível superior que, na data de início da vigência desta lei, houver comprovado, através de declarações de empregadores, o exercício efetivo, durante pelo menos trinta e seis meses, das atribuições mencionadas no art. $4^{\circ}$ desta mesma lei (Lei 9.261, 1996).

A descrição das atribuições do profissional de Secretariado no ofício circular supracitado, que baliza as funções do cargo na carreira de Técnico-administrativo em Educação, baseia-se na assessoria a direções, controle de documentos, arquivos e correspondências, redação e tradução de textos, entre outras rotinas administrativas, em concordância com o apresentado na lei que regulamenta a profissão (MEC, 2005).

O profissional de secretariado e o profissional de letras

Um dos pontos a ser discutido no desenvolvimento deste trabalho é a relação estabelecida entre os profissionais graduados em Secretariado Executivo e os 
profissionais graduados em Letras na concorrência para o ingresso no serviço público federal por meio dos concursos para o cargo de Secretário Executivo nas IFES.

A Lei 11.091 aponta como requisito para ingresso no cargo de Secretário Executivo que os profissionais sejam graduados em Secretariado Executivo ou Letras, fazendo, entretanto, uma análise do perfil exigido para o desempenho das atividades inerentes ao cargo e dos perfis dos formados em ambas as áreas e explicitando que o profissional de letras não tem a formação necessária para tais atribuições (Lei 11.091, 2005).

As diretrizes curriculares do MEC para os cursos de Letras apontam que o objetivo destes cursos é formar profissionais "interculturalmente competentes, capazes de lidar, de forma crítica, com as linguagens, especialmente a verbal, nos contextos oral e escrito, e conscientes de sua inserção na sociedade e das relações com o outro" (Parecer CNE/CES 492, 2001).

Nota-se que, apesar de constar no item dois das diretrizes que trata das habilidades e competências, os cursos de Letras devem visar a formação de profissionais para atuar como "professores, pesquisadores, críticos literários, tradutores, intérpretes, revisores de textos, roteiristas, secretários, assessores culturais, entre outras atividades", sendo exigidos desses profissionais, com exceção do item "utilização de recursos de informática", conhecimentos apenas nas áreas relacionadas ao uso da língua, de linguagens e de características pedagógicas (Parecer CNE/CES 492, 2001).

Por outro lado, na formação do profissional de Secretariado, é exigido que as competências técnicas sejam desenvolvidas desde o início da graduação, uma vez que em suas diretrizes curriculares (Resolução 3, 2005) apresentam que o profissional graduado deve:

apresentar sólida formação geral e humanística, com capacidade de análise, interpretação e articulação de conceitos e realidades inerentes à administração pública e privada, ser apto para o domínio em outros ramos do saber, desenvolvendo postura reflexiva e crítica que fomente a capacidade de gerir e administrar processos e pessoas, com observância dos níveis graduais de tomada de decisão, bem como capaz para atuar nos níveis de comportamento micro-organizacional, meso-organizacional e macro-organizacional (Resolução 3, 2005).

De forma mais direta, e fazendo um paralelo entre as habilidades e competências citadas nas diretrizes curriculares (Resolução 3, 2005) e a descrição do cargo de 
Secretário Executivo da carreira de técnico-administrativo em educação apresentado por meio do Ofício Circular $n^{\circ}$ 015/2005/CGGP/SAA/SE/MEC (MEC, 2005), temos o Quadro 3:

Quadro 3. Diretrizes curriculares x descrição do cargo.

\begin{tabular}{|c|c|}
\hline Diretrizes Curriculares & Ofício circular \\
\hline $\begin{array}{c}\text { Visão generalista da organização e das peculiares } \\
\text { relações hierárquicas e intersetoriais; exercício de } \\
\text { funções gerenciais, com sólido domínio sobre } \\
\text { planejamento, organização, controle e direção. }\end{array}$ & $\begin{array}{c}\text { Assessorar direções, gerenciando informações, } \\
\text { auxiliando na execução de tarefas administrativas e em } \\
\text { reuniões, marcando e cancelando compromissos, } \\
\text { coordenar e controlar equipes e atividades. }\end{array}$ \\
\hline $\begin{array}{c}\text { Gerenciamento de informações, assegurando } \\
\text { uniformidade e referencial para diferentes usuários. }\end{array}$ & Controlar documentos e correspondências. \\
\hline $\begin{array}{c}\text { Domínio dos recursos de expressão e de comunicação } \\
\text { compatíveis como exercício profissional, inclusive nos } \\
\text { processos de negociação e nas comunicações } \\
\text { interpessoais ou intergrupais; receptividade e liderança } \\
\text { para o trabalho em equipe, na busca da sinergia. }\end{array}$ & Atender usuários externos e internos. \\
\hline $\begin{array}{c}\text { Gestão e assessoria administrativa com base em } \\
\text { objetivos e metas departamentais e empresariais. }\end{array}$ & Organizar eventos e viagens e prestar serviços em \\
\hline $\begin{array}{c}\text { Eficaz utilização de técnicas secretariais, com } \\
\text { renovadas tecnologias, imprimindo segurança, } \\
\text { credibilidade e fidelidade no fluxo de informações. }\end{array}$ & Assessorar nas atividades de ensino, pesquisa e \\
\hline
\end{tabular}

Fonte: Resolução 3 (2005) e MEC (2005)

As habilidades e competências descritas nas diretrizes curriculares ainda abrangem outros assuntos como o uso de recursos tecnológicos e o desenvolvimento de habilidades visando à qualidade do serviço prestado. Com base nas exigências apresentadas para a formação do profissional, e a descrição dos cargos da carreira pública, é importante considerar o apontado por Carvalho (2009)

o concurso público é o procedimento pelo qual a Administração afere as aptidões dos interessados em integrar seu quadro de servidores ou empregados públicos, é certo que as exigências editalícias são lícitas apenas se viabilizam esse legítimo propósito seletivo. [...] Daí porque se afirma que os requisitos devem se mostrar necessários enquanto instrumentos de escolha dos candidatos, sendo clara a sintonia com as atividades do cargo ou emprego público.

Revista de Gestão e Secretariado-GeSec, São Paulo, v. 7, n. 3, p 202-225, set./dez. 2016. 
Dado o exposto, caracteriza-se pertinente uma análise crítica da relação perfil profissional exigido e perfil profissional admitido por meio dos concursos.

\section{Análise dos dados}

Número de concursos por ano e por região geográfica

Foram identificados 110 concursos, de 73 diferentes IFES, que disponibilizaram vagas para o cargo de Secretário Executivo durante o período estudado (2009-2015), conforme indicado no Quadro 4. Para cada IFES foi contabilizado um edital. Para as IFES que possuíam vagas para diferentes campi, em um mesmo edital, foi contabilizado apenas um edital.

Foram retirados da amostra estudada os concursos referentes ao edital 01 de 2009 da Universidade de Brasília (UNB/DF) e ao edital 40 de 2014 da Universidade Federal de Ciências da Saúde de Porto Alegre (UFCSPA/RS), pois eles eram destinados a cadastro de reserva, portanto, não seria possível analisar o número de vagas para o cargo de Secretário Executivo.

Quadro 4. Quantidade de editais por ano estudado.

\begin{tabular}{|c|c|}
\hline Ano & $\begin{array}{l}\text { Quantidade } \\
\text { de editais }\end{array}$ \\
\hline 2009 & 20 \\
\hline 2010 & 21 \\
\hline 2011 & 2 \\
\hline 2012 & 11 \\
\hline 2013 & 24 \\
\hline 2014 & 21 \\
\hline 2015 & 11 \\
\hline \multicolumn{2}{|c|}{ Total } \\
\hline \multicolumn{2}{|c|}{ Fonte: Elaborado pelas autoras }
\end{tabular}

É importante ressaltar que o baixo número de concursos nos anos de 2011, 2012 e 2015 é reflexo dos números de 2009, 2010, 2013 e 2014; pois quando um concurso está 
em vigor, não é possível que outro para o mesmo cargo e campus seja aberto e, usualmente, os concursos vigoram por dois anos.

Os 110 editais que disponibilizaram vagas para o cargo de Secretário Executivo foram oriundos de 73 IFES, ou seja, aproximadamente $68 \%$ das IFES brasileiras abriram concurso para o cargo no período analisado (2009-2015).

O Gráfico 1 representa a localização, por região geográfica, das 107 IFES do Brasil. A região Sudeste possui a maior concentração (34); seguida pela região Nordeste (29); Norte e Sul (com 17 cada uma) e Centro-oeste (10).

Gráfico 1. Localização das IFES por região geográfica.

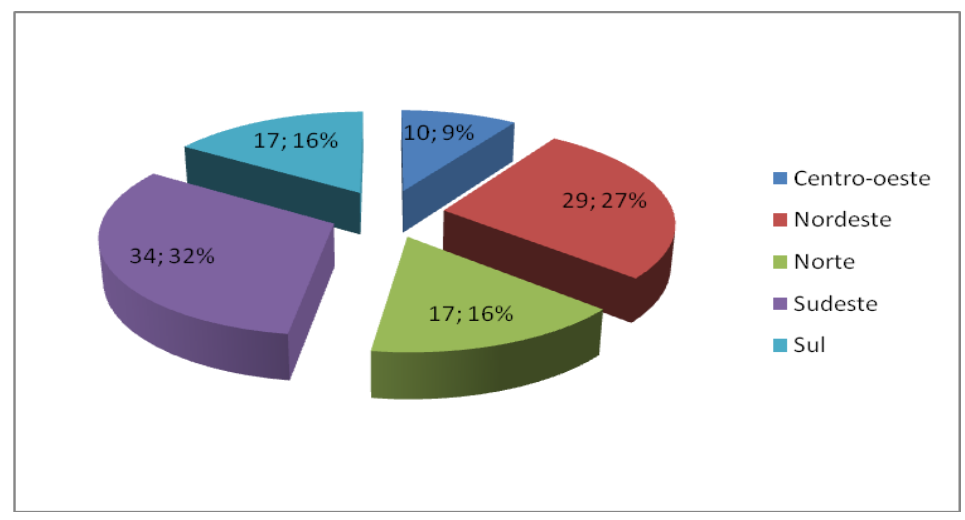

O Quadro 5 apresenta a distribuição dos 110 concursos por região geográfica. Observa-se que a maioria ocorreu nas regiões Nordeste e Sudeste, que de acordo com o Gráfico 1, são as regiões que possuem o maior número de IFES.

Quadro 5. Quantidade de editais por região geográfica.

\begin{tabular}{|l|c|c|c|c|c|}
\hline Ano & Centro-oeste & Nordeste & Norte & Sudeste & Sul \\
\hline 2009 & 1 & 5 & 2 & 8 & 4 \\
\hline 2010 & 2 & 6 & 2 & 5 & 6 \\
\hline 2011 & 1 & 0 & 0 & 1 & 0 \\
\hline 2012 & 1 & 5 & 2 & 1 & 2 \\
\hline 2013 & 3 & 6 & 8 & 4 & 3 \\
\hline 2014 & 2 & 7 & 5 & 6 & 1 \\
\hline 2015 & 2 & 3 & 1 & 5 & 0 \\
\hline
\end{tabular}


O estado que mais realizou concursos no período estudado (2009-2015) foi o estado de Minas Gerais (13), seguido do Pará (9) e Bahia (8). Minas Gerais é o estado que possui o maior número de IFES (17), portanto, pode se justificar o maior número de ofertas de editais para este estado. Porém, o Pará possui cinco IFES e foi o segundo estado com o maior número de concursos ofertados no período de 2009-2015, ultrapassando o estado do RJ que possui 10 IFES e abriu sete concursos.

O Quadro 6 apresenta o número de editais ofertados por estado brasileiro no período estudado (2009-2015).

Quadro 6. Quantidade de editais por estado.

\begin{tabular}{|c|c|c|c|c|c|c|c|c|}
\hline Estado & 2009 & 2010 & 2011 & 2012 & 2013 & 2014 & 2015 & Total \\
\hline $\mathrm{AC}$ & & 1 & & & & 1 & & 2 \\
\hline $\mathrm{AL}$ & & 1 & & 1 & & & & 2 \\
\hline $\mathrm{AM}$ & & & & & 1 & 1 & & 2 \\
\hline $\mathrm{AP}$ & & & & & 1 & & & 1 \\
\hline BA & 1 & & & 1 & 1 & 3 & 2 & 8 \\
\hline $\mathrm{CE}$ & & 1 & & & 1 & 2 & & 4 \\
\hline DF & & 1 & & & 1 & & & 2 \\
\hline $\mathrm{GO}$ & 1 & 1 & & 1 & & 1 & 1 & 5 \\
\hline $\mathrm{ES}$ & 1 & & 1 & & 1 & & & 3 \\
\hline MA & 2 & & & & & & & 2 \\
\hline $\mathrm{MG}$ & 2 & 3 & & 1 & 1 & 2 & 4 & 13 \\
\hline MS & & & & & 1 & & & 1 \\
\hline MT & & & 1 & & 1 & 1 & 1 & 4 \\
\hline PA & 1 & 1 & & 2 & 3 & 1 & 1 & 9 \\
\hline $\mathrm{PB}$ & 2 & & & 2 & 1 & & & 5 \\
\hline $\mathrm{PE}$ & & 2 & & & 2 & 1 & 1 & 6 \\
\hline PR & 1 & 2 & & & 2 & 1 & & 6 \\
\hline RJ & 3 & 1 & & & 1 & 1 & 1 & 7 \\
\hline RN & & 2 & & & 1 & & & 3 \\
\hline RO & & & & & 1 & 1 & & 2 \\
\hline $\mathrm{RR}$ & & & & & 2 & & & 2 \\
\hline $\mathrm{RS}$ & 2 & 3 & & 1 & 1 & & & 7 \\
\hline $\mathrm{SC}$ & 1 & 1 & & 1 & & & & 3 \\
\hline SP & 2 & 1 & & & 1 & 3 & & 7 \\
\hline SE & & & & 1 & & 1 & & 2 \\
\hline TO & 1 & & & & & 1 & & 2 \\
\hline
\end{tabular}

Fonte: Elaborado pelas autoras

Revista de Gestão e Secretariado-GeSec, São Paulo, v. 7, n. 3, p 202-225, set./dez. 2016. 
$\mathrm{O}$ estado que teve o menor número de editais ofertando vagas para o cargo de Secretário Executivo foi o do Amapá, com apenas um no ano de 2013, com a oferta de oito vagas, porém, sem a exigência de habilitação profissional.

Número de vagas e solicitação do registro profissional nos editais

Por meio dos 110 concursos identificados no período estudado (2009-2015), 531 vagas foram disponibilizadas, em edital, para o cargo de Secretário Executivo. $\mathrm{O}$ ano de 2010 foi o que mais ofertou vagas para o cargo, totalizando 156. No período estudado, o ano de 2013 foi o que mais teve concursos abertos (24). Entretanto, não foi o ano que mais ofertou vagas, totalizando 99.

Das 531 vagas ofertadas, somente 308 (de 57 concursos) exigiam, de alguma forma, registro/habilitação profissional, conforme detalhamento no Quadro 7. O ano de 2010, além de ter sido o ano com a maior oferta de vagas, foi o ano no qual a exigência de habilitação profissional teve o maior número (103). No ano de 2015, apenas dois concursos não exigiram habilitação profissional, ambos no estado da Bahia, estado este que no período estudado, não se exigiu habilitação profissional em nenhum dos concursos abertos.

Quadro 7. Número de vagas, por ano, destinadas a candidatos habilitados profissionalmente, de acordo com a Lei 7.377/85 e Ofício circular nº 015/2005 do MEC.

\begin{tabular}{|c|c|c|c|}
\hline Ano & Vagas & Vagas com exigência de habilitação profissional & Quantidade de editais \\
\hline 2009 & 103 & 80 & 13 \\
\hline 2010 & 156 & 103 & 12 \\
\hline 2011 & 2 & 1 & 6 \\
\hline 2012 & 53 & 27 & 5 \\
\hline 2013 & 99 & 25 & 11 \\
\hline 2014 & 96 & 56 & 9 \\
\hline 2015 & 22 & 16 & $\mathbf{5 7}$ \\
\hline Total & $\mathbf{5 3 1}$ & $\mathbf{3 0 8}$ & \multicolumn{1}{|c|}{} \\
\hline
\end{tabular}

Fonte: Elaborado pelas autoras 
Sendo assim, aproximadamente 58\% das vagas destinadas ao cargo de Secretário Executivo estão reguladas pela Lei 7377 , de 30/9/85 e Lei 9.261, de 10/01/96. De acordo com esta lei, considera-se

I - Secretário-Executivo: (Redação dada pela Lei no 9.261, de 10.1.1996)

a) o profissional diplomado no Brasil por Curso Superior de Secretariado, legalmente reconhecido, ou diplomado no exterior por Curso Superior de Secretariado, cujo diploma seja revalidado na forma da lei; (Incluído pela Lei n ${ }^{\circ}$ 9.261, de 10.1.1996)

b) portador de qualquer diploma de nível superior que, na data de início da vigência desta lei, houver comprovado, através de declarações de empregadores, o exercício efetivo, durante pelo menos trinta e seis meses, das atribuições mencionadas no art. $4^{\circ}$ desta lei; (Incluído pela Lei nº 9.261, de 10.1.1996).

O Quadro 8 apresenta a porcentagem das vagas que exigiam habilitação profissional no período de 2009-2015. O ano de 2009 apresenta o maior porcentual, 77,67\%. Porém, no ano de 2013 houve um decréscimo muito grande na média, com apenas $25,25 \%$ das vagas destinadas a profissionais com habilitação profissional.

Quadro 8. Porcentagem das vagas que exigiram habilitação profissional no período de 2009-2015.

\begin{tabular}{|c|c|}
\hline Ano & $\begin{array}{c}\text { Porcentagem das vagas } \\
\text { que exigiram habilitação profissional (\%) }\end{array}$ \\
\hline 2009 & 77,67 \\
\hline 2010 & 66,03 \\
\hline 2011 & 50,00 \\
\hline 2012 & 50,94 \\
\hline 2013 & 25,25 \\
\hline 2014 & 58,33 \\
\hline 2015 & 72,73 \\
\hline
\end{tabular}

Fonte: Elaborado pelas autoras

Verificou-se que um número elevado de vagas (223) ofertadas em concursos para profissionais que não atendiam o disposto no Ofício Circular $\mathrm{n}^{\circ}$ 015/2005 do MEC, o qual requer habilitação profissional para investidura em diversos cargos, inclusive no de secretário executivo.

Conforme detalhado no artigo de Oliveira e Moraes (2014, p. 53)

de acordo com a lei que regulamenta o PPCTAE, o requisito para ingresso no cargo de secretário executivo é "Curso Superior em Letras ou Secretário [sic] Executivo Bilíngue”. 
(Lei 11.091, 2005). Entretanto, posterior a esta lei, foi divulgado o Ofício Circular $n^{\circ}$ 015/2005/Coordenação Geral de Gestão de Pessoas/Subsecretaria de Assuntos Administrativos/Secretaria Executiva/Ministério da Educação (Ministério da Educação e Cultura $[\mathrm{MEC}], 2005)$, onde o cargo de secretário executivo pertence ao nível de classificação E, Código na Classificação Brasileira de Ocupações (CBO) 2523-05 e requisito de qualificação para ingresso no cargo:

ESCOLARIDADE: Curso Superior em Letras ou Secretariado Executivo Bilíngue OUTROS:

HABILITAÇÃO PROFISSIONAL: Lei nº 7.377, de 30 de setembro de 1985 dispõe sobre a profissão de Secretário e dá outras providências. (A redação dos incisos I e II do art. $2^{\circ}$, o caput do art. $3^{\circ}$, o inc. VI do art. $4^{\circ}$ e o parágrafo único do art. $6^{\circ}$ foram alterados pela Lei no 9.261, de 10-01-1996) (MEC, 2005).

Portanto, é importante ressaltar que a diferença do Ofício supracitado para a Lei 11.091 é que o primeiro exige a habilitação profissional, além do curso de graduação de diferentes cargos descritos do PCCTAE. Ou seja, a Lei 11.091 não prevê a habilitação profissional de nenhum cargo previsto no PCCTAE. Essa obrigatoriedade está prevista no Ofício e deve ser seguida em todos os concursos para as IFES e para todos os cargos, e não apenas para alguns, como no caso do cargo para Secretário Executivo que, conforme apontado nesta pesquisa, disponibilizou 223 vagas sem a exigência de registro profissional em desacordo com o previsto na Lei de regulamentação da profissão.

Para efeitos da Lei 7.377/85, que regulamenta o exercício da profissão (e sua posterior alteração pela Lei 9.261, de 10 de janeiro de 1996), está expressa a exigência de registro na Delegacia Regional do Trabalho do Ministério do Trabalho (atual Superintendência Regional do Trabalho e Emprego - SRTE) para pleito e atuação como secretário executivo, conforme artigo $6^{\circ}$ :

Art. $6^{\circ}-\mathrm{O}$ exercício da profissão de Secretário requer prévio registro na Delegacia Regional do Trabalho do Ministério do Trabalho e far-se-á mediante a apresentação de documento comprobatório de conclusão dos cursos previstos nos incisos I e II do Art. $2^{\circ}$ desta lei e da Carteira de Trabalho e Previdência Social - CTPS (Lei 7.377, 1985).

Entretanto, observa-se pelo presente estudo que, mesmo nos editais nos quais o registro é considerado requisito básico para a investidura no cargo de Secretário Executivo, não é unânime a menção específica da lei em questão em todos aqueles que o referendam, sendo, pois, tratados em sua maioria apenas como registro na DRT ou SRTE, Conselho competente, Conselho de classe, órgão fiscalizador do exercício da profissão ou, simplesmente, sob o termo habilitação profissional. 
Esta diversidade de nomenclaturas para exigência de registro profissional faz com que profissionais que não cumprem as exigências para atuação do cargo possam tomar posse, pois a profissão de Secretário Executivo não possui Conselho de Classe.

Outra questão é a exigência da habilitação profissional, ou seja, registro na Superintendência Regional do Trabalho e Emprego, no momento da posse do candidato aprovado em concurso público. O concurso pode solicitar tal habilitação, porém se a cobrança não for realizada no ato da posse, permitirá que candidatos graduados em Letras tomem posse nos cargos destinados aos profissionais de Secretariado Executivo.

\section{CONSIDERAÇÕES FINAIS}

Observa-se que, apesar do reconhecimento e da legislação que dispõe sobre o exercício da profissão de secretário, esta muitas vezes não é totalmente aplicada, ou considerada, em concursos para ingresso nas IFES, prejudicando e até mesmo desestimulando os profissionais graduados na área.

Com o presente estudo, foi possível constatar que das 531 vagas ofertadas, somente 308 (de 57 concursos) IFES exigiram em seus editais a habilitação profissional exigida no Ofício Circular $n^{\circ}$ 015/2005 do MEC, ou seja, foi permitida a investidura no cargo de profissionais que não cumpriam a exigência do ofício supracitado para 223 vagas. Além disso, a forma como a exigência do registro profissional dispõe-se nos editais, nem sempre é suficientemente clara, possibilitando a identificação de diferentes nomenclaturas e gerando precedentes para pleito e investidura ao cargo de Secretário por profissionais de graduados em Letras.

Sendo assim, o profissional de Secretariado Executivo ainda não conta com a proteção legal efetiva do Estado, fato que precisa ser reconsiderado e estudado em nova oportunidade, uma vez que não é possível apontar causa específica que justifique o descaso das IFES e das autoridades competentes em não assegurar o exercício da conquista legal e consolidada dos direitos do secretário executivo.

Para futuros estudos, sugere-se a análise dos editais lançados em anos diferentes dos estudados nesta pesquisa. Sugere-se, também, uma análise dos conteúdos programáticos contidos nos editais dos concursos para o cargo de Secretário Executivo, com o objetivo de verificar se o referido profissional terá a concorrência de 
profissionais não qualificados no que concerne ao conteúdo exigido nos certames, além do configurado pelos editais que permitem o ingresso de profissionais graduados em letras para o cargo em questão.

\section{REFERÊNCIAS}

Cardoso Júnior, J. C. \& Nogueira, R. P. (2011). Ocupação no setor público brasileiro: tendências recentes e questões em aberto. Revista do Serviço Público, 62 (3), 237-260.

Carvalho, R. M. U. (2009). Aspectos relevantes do concurso público. Revista do Tribunal de Contas do Estado de Minas Gerais. Edição Especial - ano XXVIII

Fontainha, F. C.; Geraldo, P. H. B.; Veronese, A.; Alves, C. S.; Figueiredo, B. H. \& Waldburguer, J. (2014). Processos seletivos para contratação de servidores públicos: Brasil, o país dos concursos? Rio de Janeiro: Direito Rio.

Gil, A. C. (2002). Como elaborar projetos de pesquisa (4a. ed.) São Paulo: Atlas.

Gonçalves, C. A. \& Meirelles, A. M. (2004). Projetos e relatórios de pesquisa em administração. São Paulo: Atlas.

Halici, A.; Yilmaz, B. \& Kasimoglu, M. (2011). Employment predictions in secretarial occupation. Procedia Social and Behavioral Sciences, 24, 435-44.

Laville, C. \& Dionne, J. (1999). A construção do saber: manual de metodologia da pesquisa em ciências humanas. Porto Alegre: Artmed; Belo Horizonte: UFMG.

Lei $n^{\circ} 7.377$, de 30 de setembro de 1985 (1985, 30 de setembro). Dispõe sobre o Exercício da Profissão de Secretário, e dá outras providências. Recuperado em 12 de novembro, 2014, de http://www.planalto.gov.br/ccivil_03/leis/L7377.htm

Lei $\mathrm{n}^{\circ}$ 9.261, de 10 de janeiro de 1996 (1996, 10 de janeiro). Altera a redação dos incisos I e II do art. $2^{\circ}$, o caput do art. $3^{\circ}$, o inciso VI do art. $4^{\circ}$ e o parágrafo único do art. $6^{\circ}$ da Lei $\mathrm{n}^{\circ}$ 7.377, de 30 de setembro de 1985. Recuperado em 12 de novembro, 2014, de http://www.planalto.gov.br/ccivil_03/leis/L9261.htm\#art1

Lei $\mathrm{n}^{0}$ 11.091, de 12 de janeiro de 2005 (2005, 12 de janeiro). Dispõe sobre a estruturação do Plano de Carreira dos Cargos Técnico-administrativos em Educação, no âmbito das Instituições Federais de Ensino vinculadas ao Ministério da Educação, e dá outras providências. Recuperado em 17 de março, 2013, de http://www.planalto.gov.br/ccivil_03/_ato2004-2006/2005/lei/111091.htm

Mazulo, R. \& Liendo, S. (2010). Secretária. São Paulo: Senac. 
Melo, P. A. (2008). A autonomia universitária e seus reflexos na gestão e nos resultados de universidades brasileiras. In Laner \& C. J. (Orgs.). Indivíduo, organizações e sociedade. Rio Grande do Sul: Unijuí, pp. 247-25.

Ministério da Educação (MEC). Ofício Circular n. 015/2005. Recuperado em 24 de março, 2013, de http://portal.mec.gov.br/arquivos/pdf/canalcggp/oficios/oc01505.pdf>.

Moraes, W. S. (2014). Petismo e chavismo: variedades de capitalismo e de regulação trabalhista no Brasil e na Venezuela. Dados - Revista de Ciências Sociais, 57 (2), 359397.

Neiva, E. G. \& D’Elia, M. E. S. (2009). As novas competências do profissional de Secretariado (2a. ed.). São Paulo: IOB.

Oliveira, L. N. \& Moraes, G. C. (2014). O panorama do cargo de Secretário Executivo em uma instituição federal de ensino superior e as implicações da lei 11.091/2005. Revista de Gestão e Secretariado - GeSec, São Paulo, vol. 5, n. 2, pp. 4971.

Oliveira, M. M. \& Silva, A. B. (2011). Gestão de pessoas por competências nas IFES: entendendo os vínculos entre a legalidade e a realidade. In Encontro de gestão de pessoas e relação de trabalho. João Pessoa: Associação Nacional de Pós-graduação e Pesquisa em Administração.

Parecer CNE/CES 492/2001. (2001, 9 de junho). Diretrizes Curriculares Nacionais dos cursos de Filosofia, História, Geografia, Serviço Social, Comunicação Social, Ciências Sociais, Letras, Biblioteconomia, Arquivologia e Museologia. Recuperado em 12 de novembro, 2014, de http://portal.mec.gov.br/cne/arquivos/pdf/CES0492.pdf

Pereira Júnior, J. T. (2009). Art. 37, incisos e parágrafos. In Bonavides, P. (org.); Miranda, J. (org.); Moura Agra, W. (org.). Comentários à Constituição Federal de 1988. Rio de Janeiro: GEN/Forense.

Resolução n. 3, de 23 de junho de 2005. (2005, 23 de junho). Institui as Diretrizes Curriculares Nacionais para o curso de graduação em Secretariado Executivo. $\begin{array}{llllll}\text { Recuperado em } & 12 & \text { de } & \text { novembro, }\end{array}$ http://portal.mec.gov.br/cne/arquivos/pdf/rces003_05.pdf

Santos, C. V. \& Caimi, F. E. (2009). Secretário Executivo: formação, atribuições e desafios profissionais. In D. G. Durante \& A. A. Fávero (Org.), Gestão secretarial: formação e atuação profissional (pp. 23-41). Passo Fundo: Ed. Universidade de Passo Fundo.

Schumacher, A. J.; Portela, K. C. A. \& Borth, M. R. (2013). Ferramentas do Secretário Executivo (2a. ed.). Cuiabá: Dos Autores. 